\title{
Understanding Arab Students' Behavioral Patterns in an Online Course: An Explanatory Study Based on Hofstede's National Cultural Dimensions
}

\author{
Ahmed Tlili 1,2,*(D), Mouna Denden ${ }^{3,4}$, Saida Affouneh ${ }^{2, *}$, Soheil Hussein Salha ${ }^{2} \mathbb{D}$, Zhenyu Cai ${ }^{1}$, \\ Mohamed Jemni ${ }^{5}$, Aras Bozkurt ${ }^{6,7, * \mathbb{D}}$, Ronghuai Huang ${ }^{1}$ and Lixin Zhu ${ }^{1, *}$ \\ 1 Smart Learning Institute, Beijing Normal University, Beijing 100875, China; zhenyu_cai@163.com (Z.C.); \\ huangrh@bnu.edu.cn (R.H.) \\ 2 Faculty of Educational Sciences and Teachers' Training, An-Najah National University, P.O. Box 7, \\ Nablus 707, Palestine; ssalha@najah.edu \\ 3 University Polytechnique Hauts-de-France, LAMIH, CNRS, UMR 8201, 59313 Valenciennes, France; \\ mouna.denden91@gmail.com \\ 4 INSA Hauts-de-France, 59313 Valenciennes, France \\ 5 Research Laboratory of Technologies of Information and Communication \& Electrical Engineering (LaTICE), \\ Tunis Higher School of Engineering (ENSIT), University of Tunis, Tunis 1008, Tunisia; \\ mohamed.jemni@fst.rnu.tn \\ 6 Distance Education Department, Open Education Faculty, Anadolu University, Eskişehir 26470, Turkey \\ 7 Department of English Studies, College of Human Sciences, University of South Africa (UNISA), \\ Pretoria 0003, South Africa \\ check for \\ updates \\ * Correspondence: ahmed.tlili23@yahoo.com (A.T.); s.affouneh@najah.edu (S.A.); \\ arasbozkurt@gmail.com (A.B.); 11112018113@bnu.edu.cn (L.Z.)
}

Citation: Tlili, A.; Denden, M.; Affouneh, S.; Salha, S.H.; Cai, Z.; Jemni, M.; Bozkurt, A.; Huang, R.; Zhu, L. Understanding Arab Students' Behavioral Patterns in an Online Course: An Explanatory Study Based on Hofstede's National Cultural Dimensions. Sustainability 2021, 13, 12426. https://doi.org/ $10.3390 /$ su132212426

Academic Editor: Łukasz Wróblewski

Received: 12 October 2021

Accepted: 4 November 2021

Published: 10 November 2021

Publisher's Note: MDPI stays neutral with regard to jurisdictional claims in published maps and institutional affiliations.

Copyright: (c) 2021 by the authors. Licensee MDPI, Basel, Switzerland. This article is an open access article distributed under the terms and conditions of the Creative Commons Attribution (CC BY) license (https:// creativecommons.org/licenses/by/ $4.0 /)$.

\begin{abstract}
The provision of online learning experiences has been implemented by many universities worldwide to overcome several challenges, including inequality in education. However, this experience is still not a common approach in public universities in the Arab region. Furthermore, several research studies have pointed out that a country's culture should be considered in order to enhance online learning, as students may behave differently based on their cultural backgrounds. Nevertheless, little is known about how a given culture may affect the learning behavioral patterns of students. Therefore, to better understand the cultural phenomenon and to enhance the adoption of online learning in the Arab region, this study aims to understand how an Arab culture may affect the online learning behaviors of students. Specifically, this study applies a lag sequential analysis (LSA) approach to understand the behavioral patterns of 116 students from Tunisia in a six-week online course. The study then further discusses the different learning behavior patterns based on the theoretical framework of Hofstede's national cultural dimensions. The findings highlight that culture can affect how students engage in online learning discussions and how they maintain their learning performance online. The findings further indicate that online learning experiences may be beneficial for female students who experience social pressures in Arab cultures.
\end{abstract}

Keywords: Hofstede's cultural dimensions; gender; online learning; Arab culture; lag sequential analysis; Tunisia

\section{Introduction}

With the rapid adoption of online and open education worldwide, several universities have started providing online learning experiences to students. This tendency has further increased during the COVID-19 pandemic, during which most universities have had to provide online courses to sustain the learning process at a distance [1]. The United Nations Educational, Scientific and Cultural Organization (UNESCO) has indicated that these online learning experiences will be the "new normal" in future education [2]. However, providing online education, especially in public universities, in the Arab region remains 
a great challenge for several reasons, including cultural issues and a lack of infrastructure and digital literacy, as well as the absence of policies supporting online education [3]. The Arab region has suffered both economically and financially compared with the rest of the world, resulting in low levels of literacy and the adoption of new education systems and methods that may improve learning experiences and outcomes. This view implies that good educational opportunities are reserved for those who are the wealthiest in society, which is a small proportion of the overall population in the Arab region [4].

To facilitate and enhance the adoption of online learning experiences for students, it is important to understand how students behave in these online spaces where, unlike with traditional learning, they need to be self-regulated, and no face-to-face meetings or discussions are conducted. Bozkurt, Yazıc1, and Aydin [5] referred to each country having its own pattern of learning behaviors that fulfil the specific criteria of that country. Consequently, a strong relationship is developed between learning behavioral patterns and culture [6]. Pratt [7] and Joy and Kolb [8] reported that culture can affect the way students behave and learn. It can be interpreted differently in the literature, and it has a broad meaning. Culture is developed collectively and reflects how members of a society see and interpret the world they live in [9]. In the context of this study, the definition of culture is "the set of attitudes, values, beliefs, and behaviors shared by a group of people, but different for each individual, communicated from one generation to the next" [10] (p. 16).

Understanding and considering a student's culture with regard to online learning may result in a more flexible and efficient learning experience, especially for students who are not familiar with the online learning experience. Matsumoto [10] further highlights that culture affects the way we receive information and process it, as well as the way we teach and learn [11], which justifies the need to examine it from different perspectives, including different cultural settings. It is also noteworthy to mention that adopting a culturally responsive learning design is also related to providing equal learning opportunities [12]. Thus, it is crucial to examine the relationship between culture and online learning, particularly from cultural contexts that have a limited number of empirical studies (e.g., Arab culture in general, and Tunisian culture specifically). On this basis, this study aims to analyze and understand the learning behaviors of Tunisian students, in a six-week fully online course, based on their culture. In this context, this study refers to Hofstede's national cultural dimensions [13] to explore and discuss the Arab (Tunisian) culture. Tunisia is situated in the Arab region and uses the French language in higher education. The gap in online education in Tunisia was further seen during the COVID-19 pandemic, where teachers, students, and administrators highlighted the many challenges in this regard [14]. While several studies have examined culture as a dimension in online learning, these studies focused on single learning action/behavior (e.g., accessing the course, time reading a given learning material, etc.). However, Shang, Xiao, and Zhang [15] reported that these single behaviors cannot reflect students' cognitive engagement and learning behavior characteristics in detail. Therefore, this study analyzes students' transition behaviors in an online course to understand how culture affects their behavioral patterns in learning. Specifically, this study relies on the lag sequential analysis (LSA) approach to analyze the students' learning behaviors. LSA is one approach within the technical domain of discovery with models, and the application area of modeling user knowledge and experience [16,17].

\section{Background}

\subsection{Impact of Culture on Online Learning}

Learning is a socially and culturally mediated phenomenon [18]. In line with this view, previous studies have shown that students' geographical regions, therefore their cultural backgrounds, may affect their online learning behaviors. This may be due to the culture and habits of that specific region. Vatrapi [19] argued that culture greatly influences social behavior, communication, cognitive processes, and pedagogical technologies, where all of them are key components in online education. Therefore, culture should be considered as a key element when designing online learning in terms of how students 
learn and what is perceived as important to learn [12]. Understanding the set of cultural and learning/teaching features will help the educational community to provide better quality, yet also culturally sensitive, instructions. Venter [20] and Anakwe, Kessler, and Christensenet [21] stated that culture can affect the tendency of students to adopt online education. For instance, Anakwe et al. [21] highlighted that students from individualistic cultures are more prone to adopt online education than collectivistic cultures. This is because distance education in general evokes different needs within individuals, including independence and self-reliance, and these needs differ from one culture to another. Similarly, Venter [20] reported that students from Asia-Pacific countries were more concerned with isolation from the instructor, who they referred to as "a figure of authority, the person with the answers" (p. 277). European students, on the other hand, expressed that isolation limits their opportunities for discussion and debate.

Gunawardena, Wilson, and Nolla [22] pointed out that discussing the importance of culture in online and distance education can be from three perspectives, namely: (1) understanding how a specific culture can affect the adoption and behaviors of students towards online and distance education (e.g., Chan [23] investigated the impact of Chinese culture on students' adoption of distance education); (2) intercultural studies focus on investigating cultural issues and clashes between individuals from different cultures taking the same distance education program (e.g., international courses); and (3) cross-cultural studies focus on comparing students from different cultures that are taking distance education programs in their own context (i.e., not in the same context as the second perspective). For instance, Gunawardena et al. [24] compared how American and Mexican students are taking distance education courses in their local universities.

Apart from the online learning behaviors of students and their relationship to their cultural backgrounds, cultural context is also related to student academic engagement [25] and performance [26], and further related to their retention or dropout rates. For instance, based on Hall's cultural classification (e.g., high and low context cultures) [27], it was found that students' cultural classification is an indicator of whether they dropout or not in an online networked learning space, such as large open online courses [28]. In all, culture is a multi-dimensional and multi-layered concept, yet the current study focuses specifically on the first perspective, which is understanding how a specific culture can affect the adoption and behaviors of students, by investigating how the Arab culture can affect the learning behaviors of Tunisian students in an online learning experience for six weeks.

\subsection{The Cultural Dimensions of Learning Based on Hofstede's Model: The Arab Culture}

Liu et al. [29] stated that there has been limited research discussing the findings related to online learning behaviors from a theoretical cultural framework. Specifically, this study refers to Hofstede's national cultural dimensions (NCD) [30] to discuss the online learning behaviors of Tunisian students. NCD was the result of a seven-year study that investigated the cultural values of the IBM staff working in 72 countries in the 1960s and 1970s [31,32]. It is considered to be one of the most influential cultural frameworks as hundreds of studies have used it to investigate cross-cultural challenges in different fields since its publication including education $[31,32]$. Despite the existence of the updated NCD with six dimensions, several research studies are still using the previous $4 \mathrm{D} / 5 \mathrm{D}$ model [12,33-35]. Thus, this study discusses the obtained findings based on the latest NCD that consists of the following six dimensions.

Power distance index (PDI) refers to the extent to which less powerful members of organizations accept and expect that power is unequally distributed. It means that inequality is endorsed both by the followers and the leaders in a society. In cultures with a high PDI, education is usually teacher-centered, and the authority (teacher) is respected and feared [36]. 
Individualism (IDV) implies the degree to which people in a society are integrated into groups. In societies with low IDV, knowledge construction can be easier via teamwork, and students rely on social relationships [12,37].

Masculinity (MAS) refers to the distribution of values between genders. Countries with high MAS encourage competition, and people from these countries are more assertive and competitive. This dimension can reflect on how an education system can focus on cooperation and security or recognition and advancement [38].

Uncertainty avoidance (UA) covers a society's tolerance for ambiguity. It indicates to what extent people feel either uncomfortable or comfortable in unstructured or unknown situations [36]. Students from cultures with high UA tend to be more comfortable in a structured curriculum with clear instructions and rules.

Long-term orientation (LTO) is related to what people choose to focus on. According to [36], people in cultures with high LTO believe that the most important events will occur in the future, whereas people with short-term orientation focus more on the present. This dimension reflects on how educational aspiration and motivation may differ from one country to another.

Indulgence (IND) reflects the degree to which a given society allows relatively free gratification of basic and natural human desires related to enjoying life and having fun [36]. In cultures with high IND, a relaxed structure governs the relationship between students and teachers [12].

Arab culture is known for its high uncertainty avoidance, where people feel more threatened by uncertain or unknown situations [39]. Influenced by this cultural feature, it can be seen that most Arab students perceived distance education very differently than students from the western world. Al-Harthi [40], for instance, found that many students from the Arab countries were anxious and resistant to take distance courses because, unlike traditional classrooms, they contain several uncertain learning scenarios. Furthermore, as the Arab culture scores well on the femininity index [39], Arab students may not want to show that they are eager to learn, resulting in limited communication and interactions in distance education [40].

\subsection{Gender and Culture Impact on Learning}

Several studies have investigated the impact of gender on online learning, and how male and female students may behave differently in online learning environments [41-43] The behaviors of individuals, even those that are considered to be biologically determined, such as gender, are governed by culture $[44,45]$. Cultural universals in gender differences are often explained by similarities in socialization practices, while cultural differences are attributed to differences in socialization. For instance, in China, Japan, and the United States, mothers expect boys to be better at mathematics and girls to be better at reading [46], although both sexes perform equally well in some aspects of both disciplines.

Norris and Inglehar [47] pointed out that the main cultural gap between Arab and Western culture is gender equality, as Arab countries remain one of the most conservative societies in the world. Additionally, one feature related to Arab culture is a woman's constant concern regarding society's perception of her family or family name and honor [40]. Therefore, interacting with men, even in classrooms, has always been restricted in some Arab countries [40] and, thus, has become a challenge. This feature, on the other hand, means that distance education is a good opportunity for female students to learn without social pressure and through interactions online [40]. Motivated by this context, this study takes one step further to understand how gender in a given culture (Arab culture in this study) may also affect online learning behaviors.

\subsection{Rationale and Research Questions}

Based on the background above, the design of a successful online learning experience requires careful analysis of students' culture. Hall [27] claimed that culture is communication, which defines the ways of "creating, sending, storing, and processing information. 
Communication underlies everything" (p. 53). Gunawardena et al. [22] stated that communication is everything in online contexts, therefore designing culturally sensitive online learning environments is crucial to facilitate knowledge transferral and processing.

However, despite the fact that providing open and online learning with different modalities is the new learning tendency worldwide [48], providing online courses is not a common learning strategy in Arab public universities. Hamdan [49] stated that this shift from traditional to online learning may also affect the learning culture of Arab students such as the Saudi Arabian students, hence questioning the definition of "traditional learning". This calls for further investigation into how Arab culture may impact online learning. Specifically, in Tunisia, the establishment of a free and public higher education system has led to several challenges, including limited university budgets, overloaded classrooms, and a lack of basic student services and infrastructure [50], resulting in limited experiences of adopting online courses. Therefore, to facilitate online learning adoption in the Arab region generally, and in Tunisia specifically_by identifying the online learning variables and behaviors that Tunisian students perceive to be most important based on their Arab culture-this study explores how Tunisian students would behave and learn in an online learning process based on Hofstede's national cultural dimensions.

The originality of the study stems from extending the existing literature in three different ways: (1) while several studies have discussed the impact of culture on online learning, no study, to the best of our knowledge, has discussed the impact of the Arab culture on online learning based on a theoretical framework, which is NCD in this study; (2) most studies that have discussed the impact of culture and/or gender on learning behaviors used simple self-report instruments (e.g., [12]); therefore, this study relies on the analysis of students' log data from a learning management system, which is a more natural form of data interaction, to investigate the impact of culture on online learning behaviors; and (3) those limited studies that analyzed the log data of students mostly focused on single learning behaviors. Shang, Xiao, and Zhang [15] reported that these single behaviors cannot reflect students' cognitive engagement and learning behavior characteristics in detail. Yang, Wang, and Li [51], on the other hand, claimed that investigating the behavior transformation sequence can fully explain how students engaged in a given a course and their cognitive behaviors. Moreover, fueled by the sudden shift to online learning and online globalization across the world [48], online learning has drawn a lot attention and gained more significance. However, beyond the technical aspects and capacity increases, the user experience is one of the most important issues for learning design [52], and culture, as a variable that informs how we learn, is also considered to be an indicator of the user experience [53], providing a rationale and justification for the current study.

Based on the aforementioned context and needs, this study analyzes the behavioral patterns of Tunisian students to understand how they would engage within an online course based on the NCD framework. To summarize, this study aims to answer the following two research questions:

RQ1. How do Tunisian students behave in an online course according to Hofstede's national cultural dimensions?

RQ2. How does gender impact online learning behavioral patterns in an online course according to Hofstede's national cultural dimensions?

\section{Methodology}

\subsection{Study Design}

To seek answers to the research questions, this six-week study adopted the quantitative research paradigm and followed an explanatory methodology [54], as this method enabled a better understanding of a specific problem that was not well investigated in the literature. To the best of our knowledge, no evidence was found in the literature that could explain how the Arab culture may impact the behavioral patterns of Tunisian students in an online course. Figure 1 shows the scores of the six of Hofstede's national cultural dimensions (described above) for Tunisia, which were obtained using the Hofstede's online tool [55]. 
This tool has been used in several studies to investigate the cultural scores in a given country. It should be noted that the dimension scores related to LTO and IND were missing using this tool. Therefore, these scores were obtained based on these two references $[31,56]$. Specifically, Triki et al. [31] found that the LTO score for Tunisia is 26, while Messener [56] found that the IND score for Tunisia is 34 .

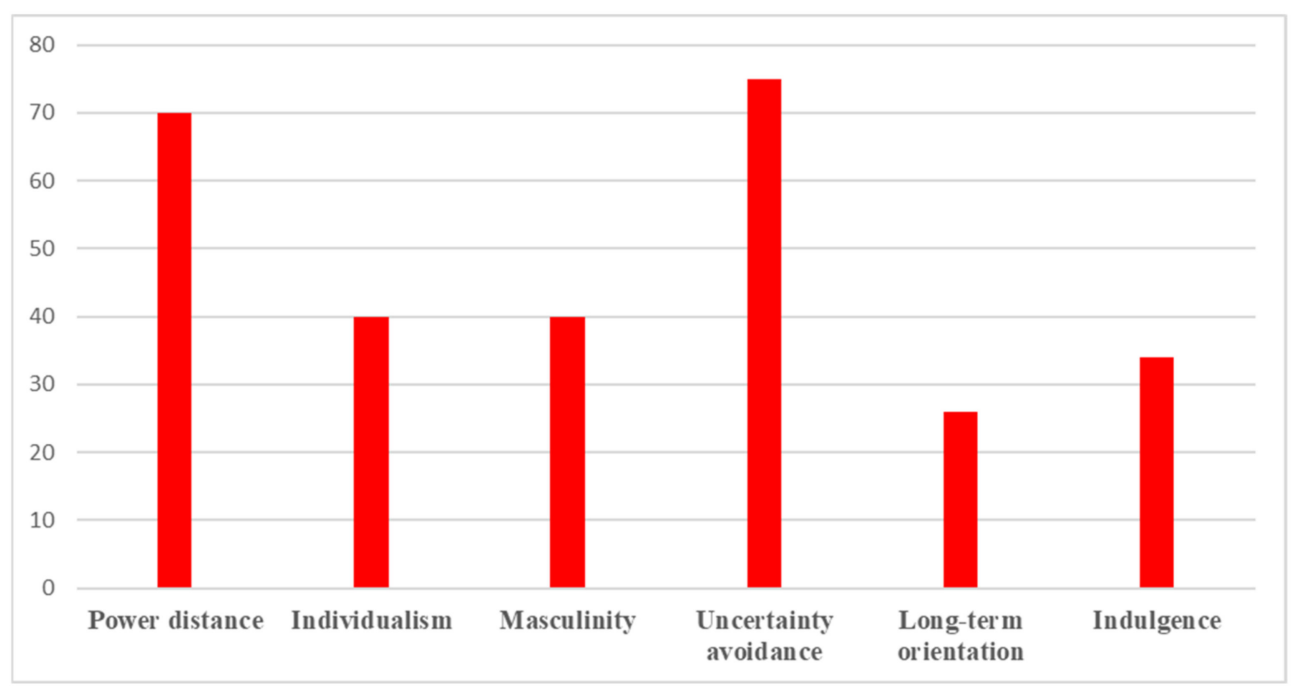

Figure 1. Scores of the six Hofstede's national cultural dimensions for Tunisia.

This study was carried out in two stages. In the first stage, the students' behavioral data (which was automatized through Moodle) was collected, and in the second, a quantitative analysis was applied to draw conclusions. The students' permission was obtained prior to conducting this research.

\subsection{Study Context: Course Design}

A six-week online course was prepared by the Smart Learning Institute of Beijing Normal University (China) in collaboration with the University of Tunis (Tunisia) for novice students learning about educational technology. This course was optional (i.e., not mandatory) and it aimed to familiarize the students with educational technology and design concepts. All the students who enrolled in this course were requested to fill in their profile information (e.g., university, country, competencies, interests, etc.) on Moodle. For each course module (one week), the students were required to work through different learning materials (videos, PDF, etc.) and upload different written assignments as requested by the teachers. For each completed module, the students earned a course badge. The students also had the option to view their course report, which included the number of completed assignments/modules and the received grades.

The students had the option to freely use the course forum to post their questions and to communicate with their peers; however, this task was not mandatory (i.e., it depended on the students' willingness). In this context, at the beginning of the course, the teacher encouraged the students to post their questions in the course forum so that their peers could help them. The teacher also asked the students to send him a Moodle message if they had any further questions.

Furthermore, the course assessment was based on the assignments uploaded online by the students, where the teacher graded them and provided written feedback to further guide them based on their assignment performance. Therefore, the role of the teacher was more as a facilitator, where he encouraged the students online by giving feedback and joining their forum discussions, as needed.

As shown in Figure 2a, the students were required to work through different learning materials (e.g., video lectures and PDF resources) each week with a final assignment to finish (see Figure $2 b$ ). The students could go to the "Design and Learning Forum" (see 
Figure 2a) to interact with their peers or to ask questions. Finally, the students had the option to see a list of their peers, as well as generate reports related to the collected badges, competencies, and grades (see Figure 2a).

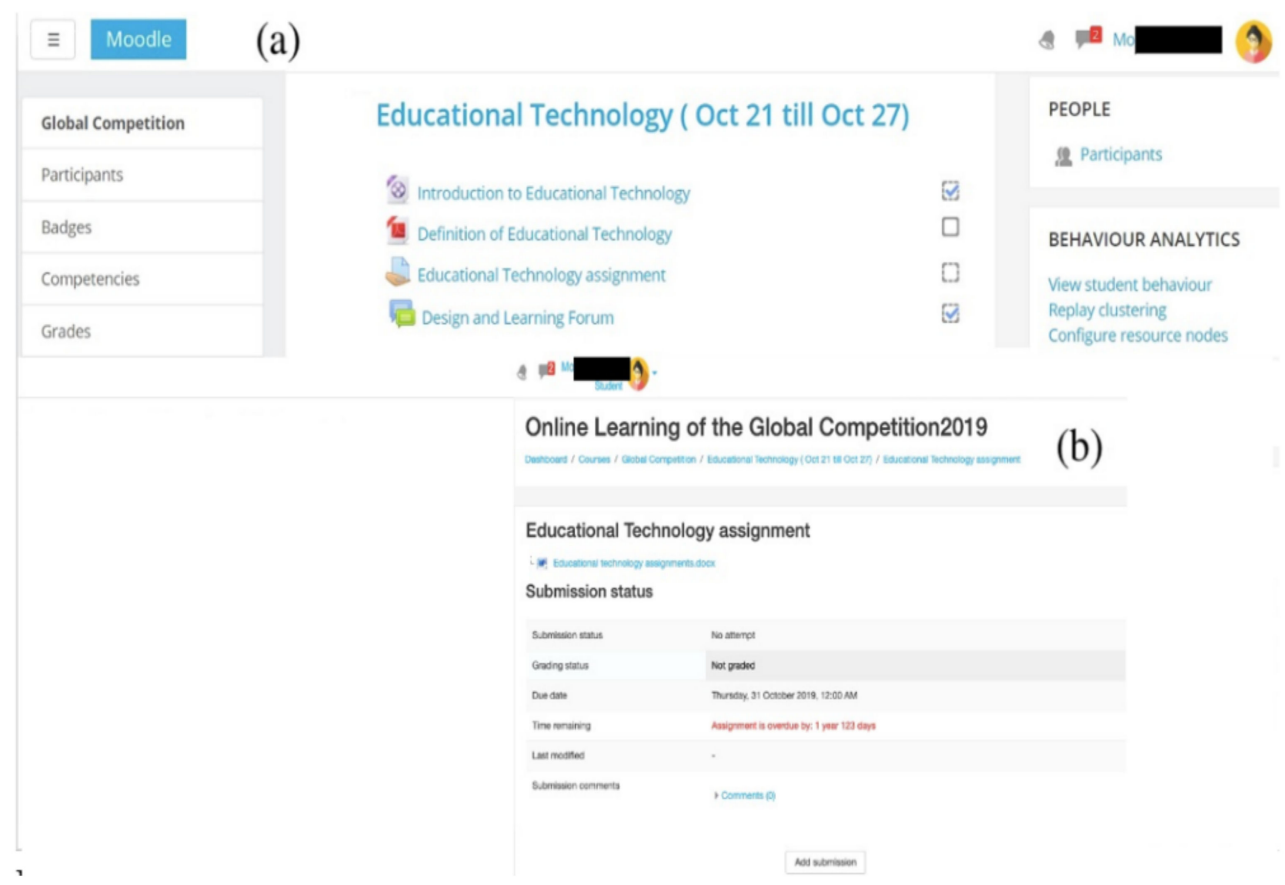

Figure 2. The Moodle system: (a) learning resources of the course, and (b) an example of an assignment submission form.

\subsection{Participants}

A total of 287 Tunisian students, aged between 21 and 24, voluntarily registered for this six-week online course after seeing the call for participation put out by their universities. All the students were majoring in education or educational technology. Among the students, only 203 ultimately enrolled in the course on Moodle. However, only 116 students (45 male and 81 female) actually finished the online learning process. Specifically, the other 87 students dropped out of the course at different phases (i.e., some students dropped out of the course in the first week, while others after a couple of weeks). This study analyzed the log data of the students who finished all the learning processes for six weeks (116 students). All the students reported that they had never taken a fully online learning experience before (i.e., without face-to-face learning).

\subsection{Research Procedures, Data, and Analysis}

The students' learning behaviors were automatically captured and stored online by Moodle. After the data cleansing process, this study collected 432,145 log data for the 116 students (described above). These log data cover 16 online learning behaviors, as shown in Table 1. For coding reliability purposes, the collected log data were independently coded by two coders [57]. Subsequently, the two coders examined the inconsistent coding results. The inter-rater reliability was 0.79 before consensus was reached. It was then increased to reach 0.92 after regular meetings between the coders to solve the coding disagreements. To identify the learning behavior patterns, lag sequential analysis (LSA) was applied using GSEQ software (version 5.1) by one of the coders. Sackett [58] proposed LSA, which aims to conduct an in-depth investigation of learning behaviors or event chains that occur at significant frequency. In education specifically, LSA considers transitional relationships to identify temporal differences in learning behaviors [59]. According to the LSA rationale, participants' behaviors were coded in the chronological order of their occurrence. For example, after reading a course (B), a student viewed the assignments $(C)$, and uploaded 
the associated answers (D); this series of behaviors was thus coded as "B C D". The zscore value of each connection between each sequence was calculated to determine if that connection reached the statistical significance. A z-score greater than 1.96 indicates that a specific sequence has reached the level of significance $(p<0.05)$. This indicates that the occurrence of that behavioral transformation sequence is significant, and not by chance [60].

Table 1. Coding of the 16 learning behaviors.

\begin{tabular}{|c|c|c|c|}
\hline Course Activity Category & Learning Activity & Description & Code \\
\hline \multirow{2}{*}{$\begin{array}{l}\text { Course module } \\
\text { viewed }\end{array}$} & $\begin{array}{l}\text { Course module } \\
\text { viewed }\end{array}$ & The student viewed the course modules & A \\
\hline & Course module completed & The student completed reading a course module & B \\
\hline \multirow{3}{*}{ Assignment submission } & Assignment form viewed & $\begin{array}{l}\text { The student viewed the assignment submission form } \\
\text { (assignment description, deadline, required working } \\
\text { time, etc.) }\end{array}$ & $\mathrm{C}$ \\
\hline & Assignment uploaded & The student submitted an assignment & $\mathrm{D}$ \\
\hline & Assignment updated & The student updated an assignment & $\mathrm{E}$ \\
\hline \multirow{5}{*}{ Social interaction } & Comment created & $\begin{array}{l}\text { The student provided a comment related to a given topic } \\
\text { within the forum }\end{array}$ & $\mathrm{F}$ \\
\hline & Discussion created & The student created a new thread within the forum & G \\
\hline & $\begin{array}{l}\text { Discussion subscription } \\
\text { created }\end{array}$ & $\begin{array}{l}\text { The student subscribed to a given discussion within the } \\
\text { forum (to receive notifications about it) }\end{array}$ & $\mathrm{H}$ \\
\hline & Discussion viewed & $\begin{array}{l}\text { The student viewed (no interaction) a given discussion } \\
\text { within the forum }\end{array}$ & I \\
\hline & Comment deleted & $\begin{array}{l}\text { The student deleted a comment related to a given } \\
\text { discussion within the forum }\end{array}$ & $\mathrm{J}$ \\
\hline \multirow{3}{*}{ Peers } & List of peers viewed & $\begin{array}{c}\text { The student saw the list of his/her peers enrolled in } \\
\text { the course }\end{array}$ & $\mathrm{K}$ \\
\hline & Peers' profile is viewed & The student saw a specific profile of the course peers & $\mathrm{L}$ \\
\hline & Peers' course report is viewed & $\begin{array}{l}\text { The student saw the achievements (completion rate, } \\
\text { grades, etc.) of the course peers }\end{array}$ & M \\
\hline \multirow{3}{*}{ Achievement result view } & Collected badge is viewed & The student saw his/her collected course badges & $\mathrm{N}$ \\
\hline & $\begin{array}{l}\text { Personal course report } \\
\text { is viewed }\end{array}$ & $\begin{array}{c}\text { The student saw his/her course report (completion rate, } \\
\text { remaining activities, etc.) }\end{array}$ & $\mathrm{O}$ \\
\hline & Grade report viewed & $\begin{array}{c}\text { The student saw his/her course grades for } \\
\text { each assignment }\end{array}$ & $\mathrm{P}$ \\
\hline
\end{tabular}

Prior to conducting LSA, a Pearson chi-square test was also conducted on the behavior frequency table of all the Tunisian students to determine if a significant dependence between rows and columns exist. Rows contain the initial behaviors, while columns contain the successive behaviors after conducting the initial ones.

\section{Results and Discussion}

\subsection{Impact of Culture on Online Learning Behavioral Patterns}

Prior to analyzing the behavioral patterns of all the Tunisian students, the mean of each (single) learning behavior was measured (see Table 2), as well as its correlation with other behaviors (see Table 3). It can be seen that the following behaviors-course module viewed (A), course module completed (B), assignment form viewed (C), assignment uploaded (D), discussion viewed (I), and list of peers viewed (K) - were the most frequent online behaviors that were also correlated with other behaviors. This could be explained by the fact that the learning culture in Tunisia is teacher-centered, where instead of supporting students by involving them in interaction, discussion, providing feedback, 
and deep thinking, the educational environments often orient students towards receiving academic content passively [61]. Consequently, even with the shift towards online learning, the passive behavior of Tunisian students persists, as they mainly conducted behaviors related to reading/uploading the learning material.

Table 2. Means and medians for the learning behaviors.

\begin{tabular}{cccc}
\hline Learning Behavior & Mean & Median & SD \\
\hline A & 41.16 & 33.50 & 35.066 \\
B & 37.93 & 42.00 & 22.758 \\
C & 5.98 & 5.00 & 5.145 \\
D & 6.41 & 8.00 & 4.764 \\
E & 0.66 & 0.00 & 1.179 \\
F & 0.06 & 0.00 & 0.462 \\
G & 0.09 & 0.00 & 0.395 \\
H & 0.25 & 0.00 & 0.922 \\
I & 5.38 & 1.00 & 13.757 \\
J & 0.01 & 0.00 & 0.093 \\
K & 8.63 & 1.00 & 27.951 \\
L & 5.17 & 2.00 & 8.296 \\
M & 0.11 & 0.00 & 0.601 \\
N & 0.61 & 0.00 & 1.581 \\
O & 1.73 & 0.00 & 6.407 \\
P & 0.12 & 0.00 & 0.420 \\
\hline
\end{tabular}

Table 3. Correlation matrix of the learning behaviors.

\begin{tabular}{|c|c|c|c|c|c|c|c|c|c|c|c|c|c|c|c|c|}
\hline Beh. & A & B & C & D & E & F & G & H & I & $\mathrm{J}$ & $\mathrm{K}$ & L & M & $\mathbf{N}$ & O & $\mathbf{P}$ \\
\hline A & & 0.850 ** & $0.755^{* *}$ & $0.732^{* *}$ & $0.512 * *$ & 0.122 & $0.345^{* *}$ & $0.297^{* *}$ & $0.485^{* *}$ & 0.155 & $0.581^{* *}$ & $0.432 * *$ & 0.176 & 0.299 ** & $0.375^{* *}$ & $0.219 *$ \\
\hline B & & & $0.705^{* *}$ & $0.662 * *$ & $0.383^{* *}$ & 0.109 & $0.296^{\text {** }}$ & $0.215^{*}$ & 0.362 ** & 0.054 & $0.495^{* *}$ & $0.348^{* *}$ & $0.209 *$ & $0.299 * *$ & $0.306^{* *}$ & 0.220 * \\
\hline C & & & & $0.874^{* *}$ & $0.710^{* *}$ & 0.183 * & $0.288^{\text {** }}$ & $0.284^{* *}$ & $0.308^{\text {** }}$ & 0.155 & 0.442 ** & $0.324^{* *}$ & $0.192 *$ & 0.185 * & 0.261 ** & 0.061 \\
\hline D & & & & & $0.804^{* *}$ & 0.089 & $0.292^{* *}$ & $0.267^{* *}$ & $0.409 * *$ & 0.128 & $0.455^{* *}$ & 0.300 ** & $0.222 *$ & $0.236^{*}$ & $0.326^{* *}$ & 0.084 \\
\hline E & & & & & & 0.089 & $0.219 *$ & $0.227^{*}$ & $0.228 *$ & 0.142 & $0.345^{* *}$ & 0.111 & 0.157 & 0.240 ** & $0.265^{* *}$ & 0.079 \\
\hline F & & & & & & & -0.036 & 0.168 & 0.043 & -0.012 & 0.009 & 0.075 & -0.028 & 0.082 & 0.072 & -0.041 \\
\hline G & & & & & & & & $0.775^{* *}$ & $0.341^{* *}$ & -0.025 & $0.272 * *$ & $0.252 * *$ & $0.286^{* *}$ & 0.151 & 0.162 & 0.167 \\
\hline $\mathbf{H}$ & & & & & & & & & $0.459 * *$ & $0.272 * *$ & $0.266^{* *}$ & 0.263 ** & $0.212 *$ & $0.185^{*}$ & $0.210^{*}$ & 0.094 \\
\hline I & & & & & & & & & & 0.168 & $0.485^{* *}$ & 0.390 ** & $0.186^{*}$ & $0.227^{*}$ & $0.249^{* *}$ & $0.209^{*}$ \\
\hline $\mathrm{J}$ & & & & & & & & & & & 0.150 & 0.062 & -0.020 & 0.169 & 0.132 & -0.029 \\
\hline $\mathrm{K}$ & & & & & & & & & & & & $0.467^{* *}$ & $0.227^{*}$ & 0.546 ** & $0.487^{* *}$ & $0.261 * *$ \\
\hline $\mathbf{L}$ & & & & & & & & & & & & & $0.230 *$ & 0.162 & $0.200 *$ & 0.005 \\
\hline $\mathbf{M}$ & & & & & & & & & & & & & & $0.200 *$ & $0.237^{* *}$ & 0.092 \\
\hline $\mathbf{N}$ & & & & & & & & & & & & & & & $0.657^{* *}$ & 0.371 ** \\
\hline $\mathrm{O}$ & & & & & & & & & & & & & & & & $0.506^{* *}$ \\
\hline $\mathbf{P}$ & & & & & & & & & & & & & & & & \\
\hline
\end{tabular}

A Pearson chi-square test was then conducted and the obtained results confirmed that there is a significant relationship between the rows and columns (the rows contain the initial behaviors, while the columns contain the successive behaviors after conducting the initial ones) of the tallied frequencies $\left(\chi^{2}=7215.71, \mathrm{df}=21, p<0.001\right)$. The sequential analysis of all the behaviors of the Tunisian students was then applied, and the results are presented in Table A1 (see Appendix A). This table shows the z-score in which students go from one kind of learning activity (in each row) to another (in each column). Based on these tables, behavior transition diagrams were drawn, as shown in Figure 3, showing those sequences that reached a significant effect. The significant sequence is the sequence with a z-score of more than 1.96 [60]. The thicker the lines, the higher the significance value.

The behavior transitions of all the Tunisian students (shown in Figure 3) were then discussed based on Hofstede's national cultural dimensions from three perspectives, 
namely experiencing the online learning nature, learning behaviors, and discussion and interaction behaviors.

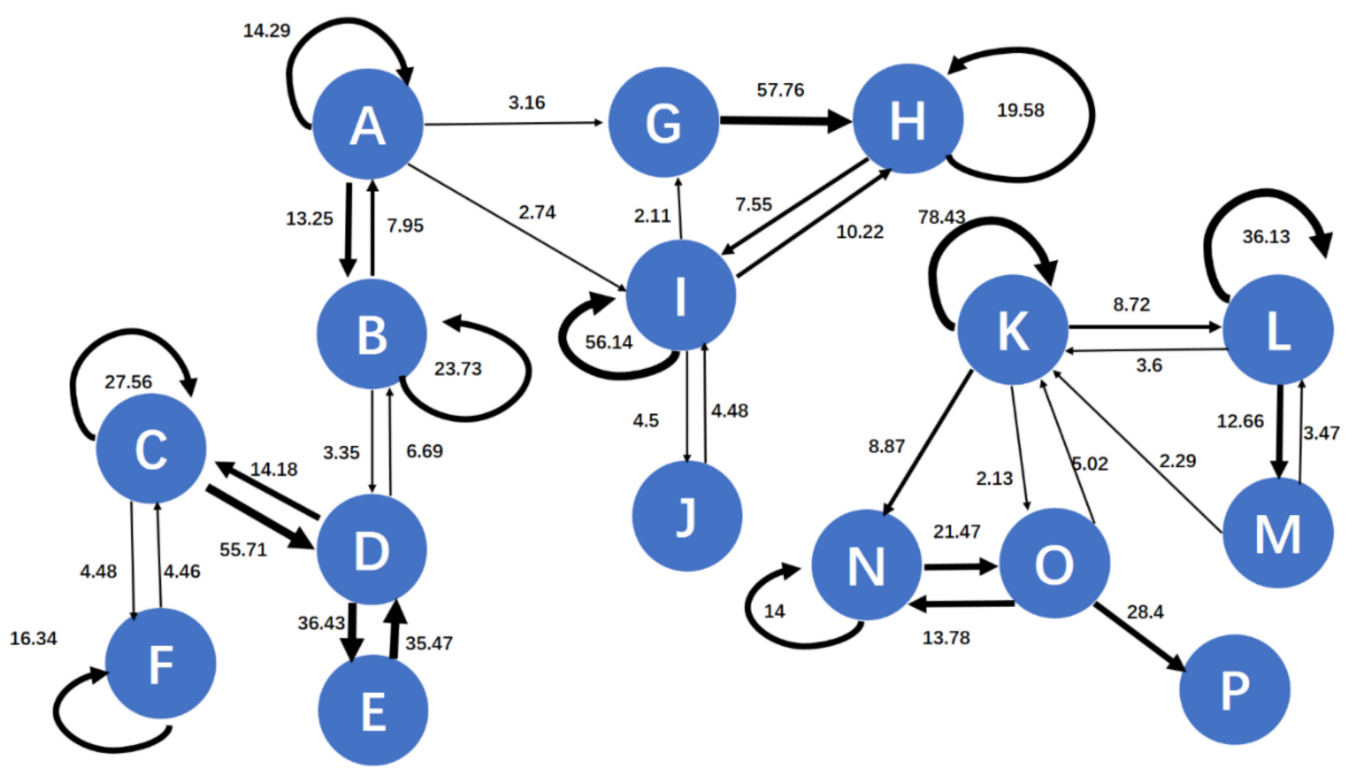

Figure 3. Behavior transition diagram of all Tunisian students.

\subsubsection{Experiencing the Online Learning Nature}

Based on the preliminary statistics, among the 287 Tunisian students who expressed an interest in enrolling in this online course and who filled in the online form, only 203 students ultimately joined the course. This shows that many Tunisian students subsequently changed their opinions due to uncertainty about online learning in their cultural context. According to Hofstede [39], countries with a high uncertainty avoidance index, such as Tunisia (see Figure 1), feel more threatened by uncertain or unknown situations. Al-Harthi [40] stated that students who are not familiar with distance education may express some anxiety towards this experience, as there are no written rules or steps on how a student should learn or behave. As Tunisian students are not familiar with such online learning experiences, they may feel stressed, since they will be in an unfamiliar and unknown learning space where the power distribution is different from their traditional learning environments. Therefore, it can be argued that many students decided to avoid this new and uncertain experience and not join the course.

Additionally, it was seen that, among the 203 Tunisian students who enrolled in this course, only 116 students finished it, while the others dropped out. Hofstede [39] argued that cultures with a low long-term orientation index, such as Tunisia (see Figure 1), focus more on the present, rather than on the future. This finding is partly in line with earlier research reporting that cultural background can be an indicator of dropout behaviors [28], and may explain why several students dropped out of this course, as they felt that it would not benefit their current situation (i.e., the course was optional, which means that taking it or not would not affect their university grades in any way). Hofstede [39] further claimed that the "long-term orientation" dimension should be considered in different cultures to increase educational motivation.

\subsubsection{Learning Behaviors}

As shown in Figure 2, the students started by gaining a generic idea about the course content by viewing each course module $(\mathrm{A} \leftrightarrow \mathrm{A})$. The students in the course then started reading each module, finishing it, uploading the associated assignments, and further updating it $(A \leftrightarrow B \leftrightarrow D \leftrightarrow E)$. It can be seen that this is a typical learning behavior that all students generally follow, regardless of their culture, where they start by seeing the whole course content to know its focus before carefully reading and finishing each part. In this 
context, Vermunt and Vermetten [62] concluded, based on several empirical studies, that "relating and structuring" is frequently observed in learning. This means that students always aim to connect the elements of the subject matter to each other and their prior knowledge before they start the learning process.

Additionally, as shown in Figure 3, the Tunisian students were open to ask and answer questions in a public realm by reading the course module, use the forums to ask questions to better understand the course content in each module, and finally to subscribe to their posts to stay updated with all the comments given by their peers $(A \rightarrow G \rightarrow H \rightarrow I)$. From a cultural perspective, based on Hofstede's model, it can be seen that Tunisia has a high power distance index and a low individualism index (see Figure 1). Therefore, it is expected that students from countries such as Tunisia with a high-power distance and low individualism indexes would probably prefer to engage with their peers in order to understand something, rather than with their teachers, as they respect their teachers and do not dare to ask them questions [12,36].

Furthermore, it was found that the students started by checking their personal course achievements, including their badges, before they started viewing the achievements of their peers $(\mathrm{O} \rightarrow \mathrm{N} \rightarrow \mathrm{K} \rightarrow \mathrm{L} \rightarrow \mathrm{M})$. This implies that all the students saw their achievements first, and then started comparing them to their peers, in order to see how they were doing in the course. Masculinity and indulgence, which are important indexes in Hofstede's model, indicate to what extent a system values cooperation or advancement, as well as leisure. According to Hofstede [39], cultures with high masculinity encourage competition, and teachers value only excellence, while cultures with low indulgence consider leisure as something less prioritized in society. As Tunisia has low indulgence indexes (see Figure 1), all the students were accomplishment-driven, valuing competition and neglecting leisure, which explains why they were more interested in their peers' performance.

\subsubsection{Behaviors on Discussion and Interaction Patterns}

As shown in Figure 3, the Tunisian students subscribed to a discussion each time they viewed it, and then deleted their comments to create a new discussion topic $(H \rightarrow I \rightarrow J \rightarrow I \rightarrow G)$. This implies that the Tunisian students used the discussions to reflect on what they learned, and further asked new questions by creating new discussion topics. These questions could be invoked while reading the discussions of their peers. Additionally, it was also seen that the Tunisian students used their involvement in the discussions to update their uploaded assignments $(\mathrm{A} \rightarrow \mathrm{B} \rightarrow \mathrm{D} \rightarrow \mathrm{C} \rightarrow \mathrm{F} \rightarrow \mathrm{C} \rightarrow \mathrm{D} \rightarrow \mathrm{E})$. These ways of using the discussions suggest that the Tunisian students tried to limit their exposure to making mistakes and to ensure the correctness of their responses. This is in accordance with Tunisia's score in the "uncertainty avoidance" dimension (see Figure 1).

Interestingly, although the Tunisian students participated significantly in the discussions (see Figure 3), the significance was not high compared to other learning behavior transitions. Hofstede [39] stated that collective cultures, such as Tunisia, depend more on high context messages. Therefore, Tunisian students who come from a collective culture may find it hard to participate online in low context messages [27]. In this context, Lewis [63] further reported that the communication style in the Arab region relies heavily on face-to-face interactions. Additionally, unlike in masculine cultures, students in feminine cultures do not want to appear too eager to do a specific task [39]. As Tunisia scores higher on the femininity index (see Figure 1), Tunisian students may decide not to show such an eagerness to learn by not highly engaging in discussions. This finding implies that lurking [64] (i.e., invisible learning) can be regarded as a form of participation.

\subsection{Impact of Gender on Online Learning Behavioral Patterns}

Prior to analyzing the behavioral patterns of the female and male students, the frequency of each (single) learning behavior was measured (see Table 4), where no significant difference was found. 
A Pearson chi-square test was then conducted and the obtained results confirmed that there is a significant relationship between the rows and columns (the rows contain the initial behaviors, while the columns contain the successive behaviors after conducting the initial ones) of the tallied frequencies $\left(\chi^{2}=9111.71, \mathrm{df}=21, p<0.001\right.$ for males; $\chi^{2}=8610.23$, $\mathrm{df}=21, p<0.001$ for females). The sequential analysis results of the male and female students' behaviors are presented in Tables A2 and A3 (see Appendix A), respectively. Based on these tables, behavior transition diagrams were drawn (as shown in Figure 4 (male students) and Figure 5 (female students)) showing those sequences that reached a significant effect. The significant sequence is the sequence with a z-score of more than 1.96 [60]. The thicker the lines, the higher the significance value.

Table 4. Results of the Mann-Whitney $U$ test for the learning behaviors.

\begin{tabular}{|c|c|c|c|c|c|}
\hline Behavior & Gender & Mean Rank & $\mathbf{Z}$ & $\mathrm{df}$ & Sig. \\
\hline A & $\begin{array}{c}\text { Male } \\
\text { Female }\end{array}$ & $\begin{array}{l}52.93 \\
62.03\end{array}$ & -1.420 & 1 & 0.156 \\
\hline $\mathrm{B}$ & $\begin{array}{c}\text { Male } \\
\text { Female }\end{array}$ & $\begin{array}{l}53.59 \\
61.61\end{array}$ & -1.253 & 1 & 0.210 \\
\hline $\mathrm{C}$ & $\begin{array}{c}\text { Male } \\
\text { Female }\end{array}$ & $\begin{array}{l}53.19 \\
61.87\end{array}$ & -1.360 & 1 & 0.174 \\
\hline $\mathrm{D}$ & $\begin{array}{c}\text { Male } \\
\text { Female }\end{array}$ & $\begin{array}{l}53.30 \\
61.80 \\
\end{array}$ & -1.352 & 1 & 0.176 \\
\hline $\mathrm{E}$ & $\begin{array}{c}\text { Male } \\
\text { Female }\end{array}$ & $\begin{array}{l}53.07 \\
61.94\end{array}$ & -1.665 & 1 & 0.096 \\
\hline $\mathrm{F}$ & $\begin{array}{c}\text { Male } \\
\text { Female }\end{array}$ & $\begin{array}{l}57.50 \\
59.13\end{array}$ & -1.131 & 1 & 0.258 \\
\hline G & $\begin{array}{c}\text { Male } \\
\text { Female }\end{array}$ & $\begin{array}{l}59.64 \\
57.77\end{array}$ & -0.664 & 1 & 0.506 \\
\hline $\mathrm{H}$ & $\begin{array}{c}\text { Male } \\
\text { Female }\end{array}$ & $\begin{array}{l}59.89 \\
57.62\end{array}$ & -0.647 & 1 & 0.518 \\
\hline I & $\begin{array}{c}\text { Male } \\
\text { Female }\end{array}$ & $\begin{array}{l}57.21 \\
59.32\end{array}$ & -0.351 & 1 & 0.726 \\
\hline $\mathrm{J}$ & $\begin{array}{c}\text { Male } \\
\text { Female }\end{array}$ & $\begin{array}{l}59.29 \\
58.00\end{array}$ & -1.256 & 1 & 0.209 \\
\hline $\mathrm{K}$ & $\begin{array}{c}\text { Male } \\
\text { Female }\end{array}$ & $\begin{array}{l}60.48 \\
57.25\end{array}$ & -0.538 & 1 & 0.591 \\
\hline $\mathrm{L}$ & $\begin{array}{c}\text { Male } \\
\text { Female }\end{array}$ & $\begin{array}{l}58.77 \\
58.33\end{array}$ & -0.069 & 1 & 0.945 \\
\hline M & $\begin{array}{c}\text { Male } \\
\text { Female }\end{array}$ & $\begin{array}{l}59.89 \\
57.62\end{array}$ & -1.006 & 1 & 0.314 \\
\hline $\mathrm{N}$ & $\begin{array}{c}\text { Male } \\
\text { Female }\end{array}$ & $\begin{array}{l}60.17 \\
57.44\end{array}$ & -0.567 & 1 & 0.574 \\
\hline $\mathrm{O}$ & $\begin{array}{c}\text { Male } \\
\text { Female }\end{array}$ & $\begin{array}{l}59.19 \\
58.06\end{array}$ & -0.211 & 1 & 0.833 \\
\hline $\mathrm{P}$ & $\begin{array}{c}\text { Male } \\
\text { Female }\end{array}$ & $\begin{array}{l}58.59 \\
58.44\end{array}$ & -0.047 & 1 & 0.963 \\
\hline
\end{tabular}

Based on Figures 4 and 5, when comparing the learning behavior transitions of the Tunisian female students to the male students, it is noted that both the Tunisian male and female students had the same learning behaviors, i.e., reading each module, finishing it, uploading the associated assignment, and further updating it ( $A \leftrightarrow B \leftrightarrow D \leftrightarrow E$ ). However, unlike the male students, it can be seen that the female students significantly participated in discussions while learning by, for instance, posting comments after viewing 
each assignment $(\mathrm{C} \rightarrow \mathrm{F})$. In addition, the female students used the discussions to further network with others and to learn more about them by seeing their profiles $(I \rightarrow L)$. This could be explained by the fact that, in the Arab culture, women monitor social boundaries in their relationships with fellow colleagues in educational or non-educational settings, meaning that they cannot easily engage in discussions with their peers due to cultural traditions and social restrictions. Hofstede [39] characterized collective cultures as "shame cultures", where he stated that "shame is social; guilt is individual" (p. 60). Therefore, unlike in face-to-face courses, female students found that this online learning experience was a way to remove social pressure and to easily engage in discussions and exchange knowledge and information with their peers. In this context, the online learning experience played a role in "face-saving", a common concept in collective cultures, which was also reported by Chan [23] and Tu [65].

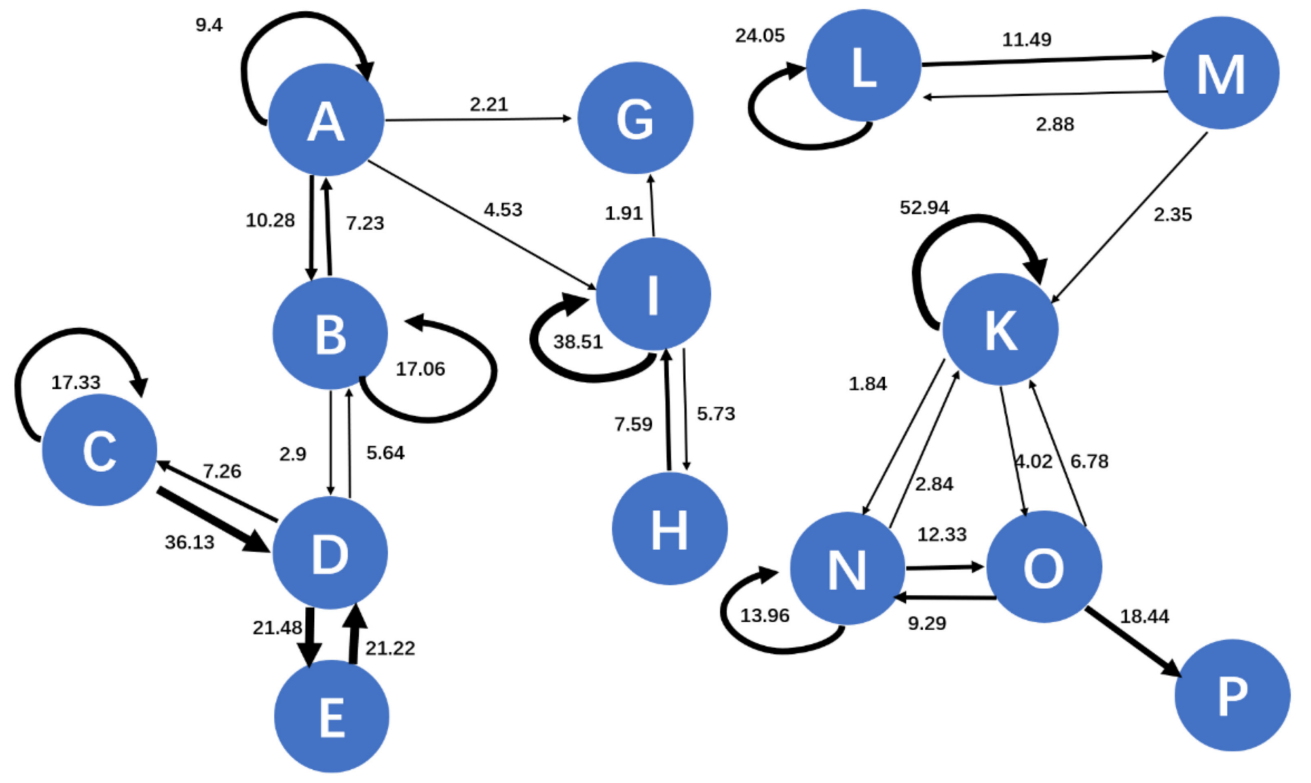

Figure 4. Behavior transition diagram of Tunisian male students.

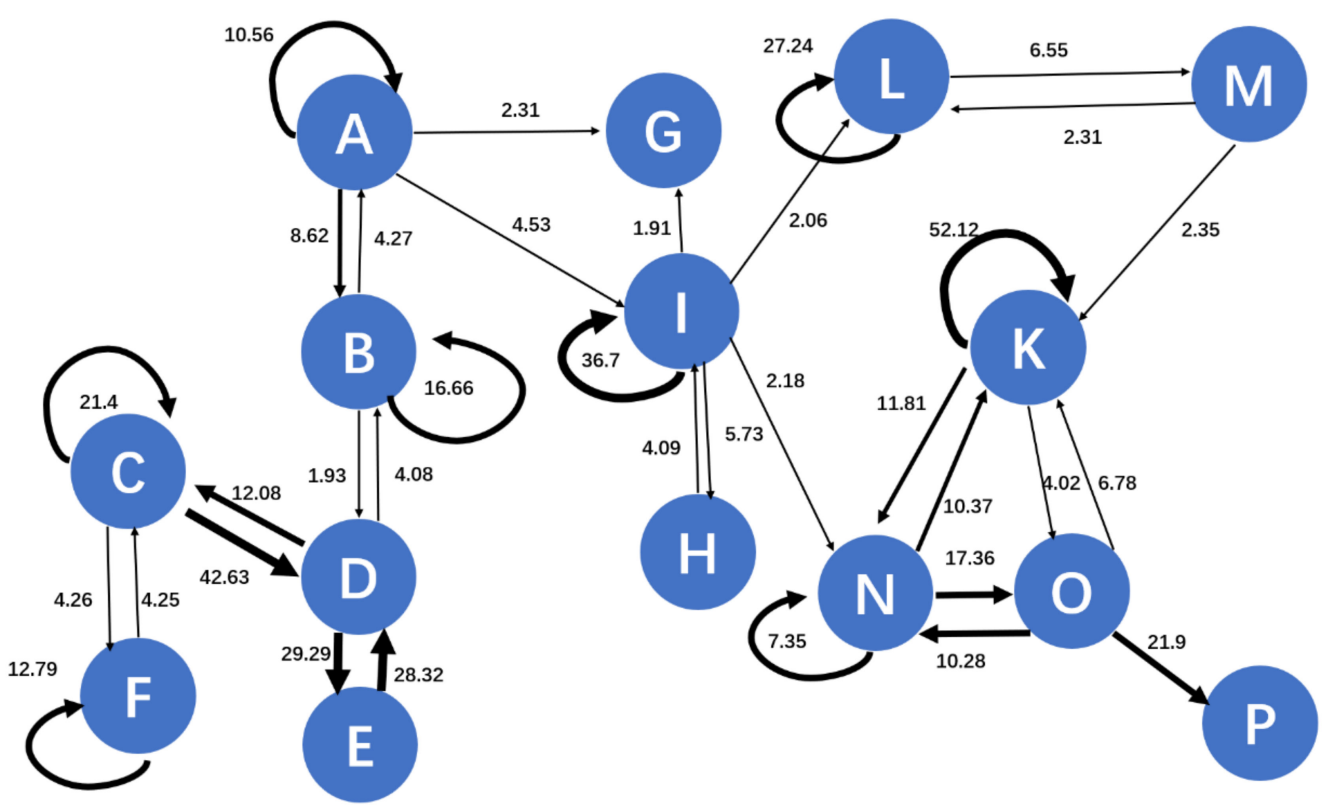

Figure 5. Behavior transition diagram of Tunisian female students. 


\section{Conclusions, Implications, and Future Research}

This paper analyzed the learning behavioral patterns of 116 Tunisian students who experienced a fully online learning course for the first time during a six-week period. The study further explored the learning behaviors in a different cultural setting through the lens of Hofstede's national cultural dimensions (NCD). The results of this study showed that a given culture can affect how students behave and interact in an online learning environment; for instance, the way they engage in discussions and make use of them. Additionally, the obtained results showed that online learning experiences can be beneficial for female students who constantly feel social pressure in Arabic cultures.

The findings of this study could help in making recommendations for understanding culturally relevant pedagogies [66] and in designing online culturally inclusive learning environments [67]. For instance, this study found that students often navigated through their peers' achievements while learning, as Arab culture values competitiveness. Therefore, to increase the learning motivation of Arab students, it may be possible to use achievement-based gamification elements in online courses, such as digital badges, points, and leaderboards [68]. Furthermore, as the Arab culture has a high femininity index, students may decide not to show others that they are eager to learn (or work hard). For instance, students may decide to download the learning materials and learn offline where no one can see that they are learning. Therefore, teachers should keep this in mind when designing learning assessment criteria by not assessing students' performance based only on their online interactions.

Although this study provides a solid basis for understanding online behaviors based on a given culture, it has some limitations that should be acknowledged. For example, the sample size was limited (only 116 students). Additionally, this explanatory study relied on Hofstede's tool to calculate the NCD values for each country, and the students did not complete any survey on cultural indicators. In particular, the study did not rely on a scenario-based approach, which could help to fully explain the obtained findings, such as why some of the students dropped out and others did not. Therefore, future research could focus on applying structural equation models to investigate how the perceived culture of students, for each of the six dimensions, could impact their online learning perceptions and behavioral patterns. Studies could also focus on investigating the cross-cultural impact on students' behaviors, by comparing how students from different cultures (e.g., Western culture) behave compared to students from the Arabic culture. This could help to draw conclusions about designing learning systems that consider the effect of the students' culture on adaptive learning. Additionally, it is suggested that future research focuses on comparing and understanding the cultural participation and communication differences in a cross-cultural online learning setting, and further focuses on identifying the design principles or walkthroughs informed by culturally relevant pedagogy.

Based on the findings of this study that investigated cultural backgrounds in online learning, the following theoretical and practical implications can be taken into consideration. From a theoretical aspect, this study contributes to an understanding of online learning and culture [69,70], and further strives to understand how the behaviors of students can be related to their cultural context. Based on the notion that instructional and learning design principles, as well as most of the online pedagogies, are Western-oriented and do not ensure culturally inclusive participation [71], this study contributes to understanding the power dynamics in online learning [72] in a different cultural context, and implies that there is a need to develop strategies for culturally inclusive learning environments. In this regard, it is proposed that future studies focus on identifying the relationships between culture and online learning by employing different theoretical or conceptual lenses, such as Hall's high-context vs. low-context cultures [27] and GLOBE societal clusters [73].

From a practical aspect, confirming the view that culture shapes our online learning experiences [74], the current study stresses the consideration of the cultural backgrounds of learners in designing online learning spaces and in the practice of online learning. Accordingly, it is suggested that instructional/learning designers can focus on reflecting 
culturally relevant pedagogies [66] to create more inclusive learning environments and to increase collaboration in cross-cultural online learning spaces [75]. Moreover, for students whose gender (e.g., female and male) and cultural codes encourage lurking, that is being less visible or being less active in learning spaces, different measures can be taken to encourage them actively participate and express themselves. In this sense, gamification to increase learner motivation and participation, designing and using ice-breaker activities to encourage learners from different cultural backgrounds, and allowing flexibility in building their digital identities (e.g., using avatars, alternative bios, etc.) are practical solutions to mitigate the side-effects of cultural backgrounds in cross-cultural online learning spaces. Apart from the aforementioned issues, this study also suggests that, in higher education institutions where international students are present, whether online or onsite, instructors can adopt motivational strategies [76] to ensure the participation of learners from different cultural backgrounds and to keep them engaged in the learning process. In addition, it is recommended that international higher education institutions pay special attention to the course orientation of students from different cultures in order to raise awareness of all parties and to eliminate cultural differences beforehand.

Author Contributions: Conceptualization, A.T. and A.B.; methodology, A.T.; software, Z.C.; validation, S.A., S.H.S. and M.J.; data curation, A.T.; writing —original draft preparation, A.T.; writing-review and editing, A.B.; visualization, S.H.S.; supervision, R.H.; project administration, M.D.; funding acquisition, L.Z. All authors have read and agreed to the published version of the manuscript.

Funding: This work was supported by the Research Funds from the Ministry of Education-China Mobile (grant number: MCM20200406).

Institutional Review Board Statement: The study was conducted according to the guidelines of the Declaration of Helsinki, and approved by the Institutional Review Board (or Ethics Committee) of The Smart Learning Institute of Beijing Normal University (date of approval: 8 August 2019).

Informed Consent Statement: Informed consent was obtained from all subjects involved in the study.

Data Availability Statement: The datasets generated and/or analyzed during the current study are not publicly available due to privacy reasons, but are available from the corresponding author on reasonable request.

Conflicts of Interest: The authors declare no conflict of interest.

\section{Appendix A}

Table A1. Z-score of navigational behaviors of all Tunisian students.

\begin{tabular}{|c|c|c|c|c|c|c|c|c|c|c|c|c|c|c|c|c|}
\hline & $\mathbf{A}$ & B & C & D & $\mathbf{E}$ & F & G & $\mathbf{H}$ & I & $\mathbf{J}$ & $\mathbf{K}$ & $\mathbf{L}$ & $\mathbf{M}$ & $\mathbf{N}$ & O & $\mathbf{P}$ \\
\hline A & 14.29 & 13.25 & -4.67 & -20.84 & -6.61 & -1.2 & 3.16 & -3.27 & 2.74 & -0.75 & -18.24 & -5.89 & -2.71 & -5.1 & -5.39 & -2.81 \\
\hline B & 7.95 & 23.73 & -10.19 & 3.35 & -6.21 & -0.26 & -2.34 & -3.8 & -17.62 & -0.71 & -20.06 & -10.57 & -2.54 & -4.44 & -7.51 & -2.64 \\
\hline C & -12.57 & -18.23 & 27.56 & 55.71 & -2.06 & 4.48 & -0.78 & -1.26 & -5.64 & -0.23 & -7.1 & -3.31 & -0.85 & -1.98 & -2.07 & -0.88 \\
\hline D & -6.74 & 6.69 & 14.18 & -5.63 & 36.43 & -0.64 & -0.8 & -1.3 & -6.18 & -0.24 & -6.62 & -4.85 & -0.87 & -1 & -1.89 & -0.9 \\
\hline E & -6.54 & -5.99 & -2.07 & 35.47 & -0.67 & -0.2 & -0.25 & -0.41 & -1.96 & -0.08 & -2.52 & -1.89 & -0.28 & -0.65 & -1.1 & -0.29 \\
\hline F & 0.4 & -1.87 & 4.46 & -0.65 & -0.2 & 16.34 & -0.08 & -0.12 & -0.59 & -0.02 & -0.76 & -0.57 & -0.08 & -0.19 & -0.33 & -0.09 \\
\hline G & -1.21 & -2.35 & -0.78 & -0.81 & -0.25 & -0.08 & -0.1 & 57.76 & -0.74 & -0.03 & -0.95 & -0.71 & -0.1 & -0.24 & -0.41 & -0.11 \\
\hline $\mathbf{H}$ & 0.26 & -3.42 & -1.27 & -1.32 & -0.41 & -0.12 & -0.16 & 19.58 & 7.55 & -0.05 & -1.54 & 0.65 & -0.17 & -0.4 & -0.67 & -0.18 \\
\hline I & -4.33 & -16.04 & -0.84 & -6.24 & -1.95 & -0.59 & 2.11 & 10.22 & 56.14 & 4.5 & -5.11 & 1.13 & -0.8 & 0.37 & 0.52 & -0.83 \\
\hline $\mathbf{J}$ & -0.74 & -0.71 & -0.24 & -0.24 & -0.08 & -0.02 & -0.03 & -0.05 & 4.48 & -0.01 & -0.29 & -0.22 & -0.03 & -0.07 & -0.12 & -0.03 \\
\hline K & -15.98 & -23.02 & -5.34 & -8.01 & -2.51 & -0.75 & -0.95 & -1.54 & -6.99 & -0.29 & 78.43 & 8.72 & -1.03 & 8.87 & 2.13 & -0.05 \\
\hline L & -0.3 & -14.52 & -1.12 & -5.71 & -1.9 & -0.57 & -0.72 & -1.17 & 0.03 & -0.22 & 3.6 & 36.13 & 12.66 & 0.48 & 0.01 & -0.81 \\
\hline $\mathbf{M}$ & -0.77 & -2.45 & -0.82 & -0.85 & -0.27 & -0.08 & -0.1 & -0.16 & -0.77 & -0.03 & 2.29 & 3.47 & 27.48 & -0.26 & -0.43 & -0.11 \\
\hline $\mathbf{N}$ & -2.8 & -5.98 & -1.99 & -2.07 & -0.65 & -0.19 & -0.24 & -0.4 & -1.88 & -0.07 & 8.39 & -1.24 & -0.27 & 14 & 21.27 & -0.28 \\
\hline O & -2.43 & -9.01 & -1.04 & -3.43 & -1.08 & -0.32 & -0.41 & -0.66 & -3.13 & -0.12 & 5.02 & -1.61 & -0.44 & 13.78 & 35.42 & 28.4 \\
\hline $\mathbf{P}$ & -2.1 & -2.55 & -0.85 & -0.88 & -0.28 & -0.08 & -0.1 & & & & & & & & & \\
\hline
\end{tabular}


Table A2. Z-score of navigational behaviors of Tunisian male students.

\begin{tabular}{|c|c|c|c|c|c|c|c|c|c|c|c|c|c|c|c|c|}
\hline & A & B & $\mathrm{C}$ & D & E & $\mathbf{F}$ & G & $\mathbf{H}$ & I & $\mathbf{J}$ & $\mathbf{K}$ & L & $\mathbf{M}$ & $\mathbf{N}$ & $\mathrm{O}$ & $\mathbf{P}$ \\
\hline A & 9.4 & 10.28 & -2.05 & -11.66 & -3.47 & 0 & 2.21 & -2.3 & 0.34 & -0.71 & -13.88 & -4.77 & -2.12 & -3.12 & -1.29 & -1.58 \\
\hline B & 7.23 & 17.06 & -4.68 & 2.9 & -3.26 & 0 & -1.49 & -2.66 & -13.2 & -0.66 & -15.44 & -5.95 & -2 & -2.03 & -4.48 & -1.49 \\
\hline C & -6.25 & -10.19 & 17.33 & 36.13 & -1.07 & 0 & -0.49 & -0.87 & -4.06 & -0.22 & -5.75 & -2.38 & -0.65 & -1.09 & -1.95 & -0.49 \\
\hline D & -2.75 & 5.64 & 7.26 & -2.3 & 21.48 & 0 & -0.51 & -0.92 & -4.54 & -0.23 & -5.65 & -2.57 & -0.69 & -1.15 & -0.48 & -0.51 \\
\hline E & -3.44 & -3.28 & -1.07 & 21.22 & -0.34 & 0 & -0.15 & -0.28 & -1.37 & -0.07 & -1.82 & -0.98 & -0.21 & -0.35 & -0.62 & -0.15 \\
\hline $\mathrm{F}$ & 0 & 0 & 0 & 0 & 0 & 0 & 0 & 0 & 0 & 0 & 0 & 0 & 0 & 0 & 0 & 0 \\
\hline G & -1.57 & -1.49 & -0.49 & -0.52 & -0.15 & 0 & -0.07 & 39.78 & -0.62 & -0.03 & -0.83 & -0.45 & -0.09 & -0.16 & -0.28 & -0.07 \\
\hline H & 0.39 & -2.13 & -0.88 & -0.93 & -0.28 & 0 & -0.13 & 4.24 & 5.66 & -0.06 & -1.49 & 0.51 & -0.17 & -0.28 & -0.5 & -0.13 \\
\hline I & -3.3 & -12.08 & -0.71 & -4.6 & -1.37 & 0 & 1.11 & 7.59 & 38.51 & 3.59 & -6.21 & 0 & -0.84 & -1.4 & 0.57 & -0.62 \\
\hline $\mathbf{J}$ & -0.7 & -0.67 & -0.22 & -0.23 & -0.07 & 0 & -0.03 & -0.06 & 3.59 & -0.01 & -0.37 & -0.2 & -0.04 & -0.07 & -0.13 & -0.03 \\
\hline K & -12.53 & -17.52 & -3.92 & -6.11 & -1.82 & 0 & -0.83 & -1.48 & -7.02 & -0.37 & 52.94 & 5.08 & -1.11 & 1.84 & -0.53 & -0.83 \\
\hline L & -3.54 & -7.67 & -1.05 & -3.31 & -0.99 & 0 & -0.45 & -0.81 & 1.63 & -0.2 & 2.03 & 24.05 & 11.49 & 3.14 & -0.63 & -0.45 \\
\hline $\mathbf{M}$ & 0.02 & -2 & -0.66 & -0.69 & -0.21 & 0 & -0.09 & -0.17 & -0.84 & -0.04 & 0.93 & 2.88 & 15.73 & -0.21 & -0.38 & -0.09 \\
\hline $\mathbf{N}$ & -1.38 & -3.35 & -1.1 & -1.16 & -0.35 & 0 & -0.16 & -0.28 & -1.4 & -0.07 & 2.44 & -1 & -0.21 & 13.96 & 12.33 & -0.16 \\
\hline 0 & 1.22 & -5.36 & -0.82 & -2.03 & -0.61 & 0 & -0.28 & -0.49 & -2.45 & -0.12 & 0.99 & -1.75 & -0.37 & 9.29 & 16.63 & 18.14 \\
\hline $\mathbf{P}$ & -1.57 & -1.49 & -0.49 & -0.52 & -0.15 & 0 & -0.07 & -0.13 & -0.62 & -0.03 & -0.83 & -0.45 & -0.09 & -0.16 & 17.79 & -0.07 \\
\hline
\end{tabular}

Table A3. Z-score of navigational behaviors of Tunisian female students.

\begin{tabular}{ccccccccccccccccc}
\hline & $\mathbf{A}$ & $\mathbf{B}$ & $\mathbf{C}$ & $\mathbf{D}$ & $\mathbf{E}$ & $\mathbf{F}$ & $\mathbf{G}$ & $\mathbf{H}$ & $\mathbf{I}$ & $\mathbf{J}$ & $\mathbf{K}$ & $\mathbf{L}$ & $\mathbf{M}$ & $\mathbf{N}$ & $\mathbf{O}$ & $\mathbf{P}$ \\
\hline $\mathbf{A}$ & 10.56 & 8.62 & -4.41 & -17.41 & -5.69 & -1.28 & 2.31 & -2.24 & 4.53 & 0 & -11.21 & -4.01 & -1.56 & -4.07 & -5.84 & -2.34 \\
$\mathbf{B}$ & 4.27 & 16.66 & -9.3 & 1.93 & -5.34 & -0.35 & -1.79 & -2.64 & -11.28 & 0 & -12.29 & -8.87 & -1.46 & -4.04 & -6.03 & -2.2 \\
$\mathbf{C}$ & -11.11 & -15.26 & 21.4 & 42.63 & -1.79 & 4.26 & -0.6 & -0.88 & -3.72 & 0 & -3.98 & -2.47 & -0.49 & -1.67 & -1.15 & -0.74 \\
$\mathbf{D}$ & -6.43 & 4.08 & 12.08 & -5.27 & 29.29 & -0.66 & -0.61 & -0.9 & -4.07 & 0 & -3.41 & -4.15 & -0.5 & -0.44 & -2 & -0.75 \\
$\mathbf{E}$ & -5.63 & -5.07 & -1.79 & 28.32 & -0.59 & -0.21 & -0.2 & -0.29 & -1.33 & 0 & -1.62 & -1.64 & -0.16 & -0.55 & -0.9 & -0.24 \\
$\mathbf{F}$ & 0.31 & -1.94 & 4.25 & -0.67 & -0.21 & 12.79 & -0.07 & -0.11 & -0.48 & 0 & -0.59 & -0.59 & -0.06 & -0.2 & -0.33 & -0.09 \\
$\mathbf{G}$ & -0.2 & -1.8 & -0.6 & -0.62 & -0.2 & -0.07 & -0.07 & 40.7 & -0.44 & 0 & -0.54 & -0.55 & -0.05 & -0.19 & -0.3 & -0.08 \\
$\mathbf{H}$ & 0.09 & -2.65 & -0.89 & -0.91 & -0.29 & -0.11 & -0.1 & 27.58 & 4.09 & 0 & -0.8 & 0.49 & -0.08 & -0.27 & -0.45 & -0.12 \\
$\mathbf{I}$ & -2.15 & -10.12 & -0.1 & -4.08 & -1.31 & -0.48 & 1.91 & 5.73 & 36.7 & 0 & -1.47 & 2.06 & -0.36 & 2.18 & 0.1 & -0.54 \\
$\mathbf{J}$ & 0 & 0 & 0 & 0 & 0 & 0 & 0 & 0 & 0 & 0 & 0 & 0 & 0 & 0 & 0 & 0 \\
$\mathbf{K}$ & -9.25 & -14.5 & -3.29 & -5.03 & -1.62 & -0.59 & -0.54 & -0.8 & -3.61 & 0 & 52.12 & 8.36 & -0.44 & 11.81 & 4.02 & 0.92 \\
$\mathbf{L}$ & 1.96 & -12.48 & -0.72 & -4.69 & -1.65 & -0.6 & -0.55 & -0.81 & -1.32 & 0 & 3.83 & 27.24 & 6.55 & -1.53 & 0.47 & -0.68 \\
$\mathbf{M}$ & -1.34 & -1.27 & -0.43 & -0.44 & -0.14 & -0.05 & -0.05 & -0.07 & -0.31 & 0 & 2.35 & 2.31 & 25.95 & -0.13 & -0.21 & -0.06 \\
$\mathbf{N}$ & -2.49 & -4.99 & -1.67 & -1.72 & -0.55 & -0.2 & -0.19 & -0.27 & -1.23 & 0 & 10.37 & -0.83 & -0.15 & 7.35 & 17.36 & -0.23 \\
$\mathbf{O}$ & -4.02 & -7.25 & -0.68 & -2.77 & -0.89 & -0.32 & -0.3 & -0.44 & -1.99 & 0 & 6.78 & -0.72 & -0.24 & 10.28 & 32.14 & 21.9 \\
$\mathbf{P}$ & -1.45 & -2.08 & -0.69 & -0.72 & -0.23 & -0.08 & -0.08 & & & & & & & & & \\
\hline
\end{tabular}

\section{References}

1. Huang, R.; Liu, D.; Tlili, A.; Knyazeva, S.; Chang, T.W.; Zhang, X.; Holotescu, C. Guidance on Open Educational Practices during School Closures: Utilizing OER under COVID-19 Pandemic in Line with UNESCO OER Recommendation; Smart Learning Institute of Beijing Normal University: Beijing, China, 2020.

2. UNESCO. The New Normal-What Needs to Be Different than before? Available online: https://en.unesco.org/ futuresofeducation/debates/the-new-normal (accessed on 27 August 2021).

3. Matar, N.; Hunaiti, Z.; Halling, S.; Matar, Š. E-Learning acceptance and challenges in the Arab region. In ICT Acceptance, Investment and Organization: Cultural Practices and Values in the Arab World; IGI Global: Hershey, PA, USA, 2011; pp. 184-200.

4. Cassidy, T.; Matthew, M. Higher education in the ARAB states: Responding to the challenges of globalization. In Proceedings of the AMIDEAST Conference on Higher Education, ARAB Countries, Marrakesh, Morocco, 13 March 2002.

5. Bozkurt, A.; Yazıcı, M.; Aydın, İ.E. Cultural diversity and its implications in online networked learning spaces. In Supporting Multiculturalism in Open and Distance Learning Spaces; IGI Global: Hershey, PA, USA, 2018; pp. 56-81.

6. Yamazaki, Y. Learning styles and typologies of cultural differences: A theoretical and empirical comparison. Int. J. Intercult. Relat. 2005, 29, 521-548. [CrossRef]

7. Pratt, D.D. Conceptions of self within China and the United States. Int. J. Intercult. Relat. 1991, 15, 285-310. [CrossRef]

8. Joy, S.; Kolb, D.A. Are there cultural differences in learning style? Int. J. Intercult. Relat. 2009, 33, 69-85. [CrossRef]

9. Powell, G. On being a culturally sensitive instructional designer and educator. Educ. Technol. 1997, 37, 6-14.

10. Matsumoto, D. Culture and Psychology; Brooks/Cole Publishing Company: Pacific Grove, CA, USA, 1996.

11. Bates, T. International distance education: Cultural and ethical issues. Distance Educ. 2001, 22, 122-136. [CrossRef]

12. Gómez-Rey, P.; Barbera, E.; Fernández-Navarro, F. The Impact of cultural dimensions on online learning. J. Educ. Technol. Soc. 2016, 19, 225-238.

13. Hofstede, G. Cultural differences in teaching and learning. Int. J. Intercult. Relat. 1986, 10, 301-320. [CrossRef]

14. Joyce, P.; Maron, F.; Reddy, P.S. (Eds.) Good Public Governance in a Global Pandemic; International Institute of Administrative Sciences: Brussels, Belgium, 2020.

15. Shang, J.; Xiao, R.; Zhang, Y. A Sequential analysis on the online learning behaviors of Chinese adult learners: Take the KGC learning platform as an example. In Blended Learning. Education in a Smart Learning Environment; Springer: Cham, Switzerland, 2020; pp. 61-76.

16. Knight, S.; Wise, A.F.; Chen, B. Time for change: Why learning analytics needs temporal analysis. J. Learn. Anal. 2017, 4, 7-17. [CrossRef]

17. Zhang, J.; Gao, M.; Holmes, W.; Mavrikis, M.; Ma, N. Interaction patterns in exploratory learning environments for mathematics: A sequential analysis of feedback and external representations in Chinese schools. Interact. Learn. Environ. 2019, 29, 1-18. [CrossRef]

18. Groulx, J.G.; Silva, C. Evaluating the development of culturally relevant teaching. Multicult. Perspect. 2010, 12, 3-9. [CrossRef] 
19. Vatrapi, R.V. Cultural considerations in computer supported collaborative learning. Res. Pract. Technol. Enhanc. Learn. 2008, 3, 159-201. [CrossRef]

20. Venter, K. Coping with isolation: The role of culture in adult distance learners' use of surrogates. Open Learn J. Open Distance e-Learn. 2003, 18, 271-287. [CrossRef]

21. Anakwe, U.P.; Kessler, E.H.; Christensen, E.W. Distance learning and cultural diversity: Potential users' perspective. Int. J. Organ. Anal. 1999, 7, 224-243. [CrossRef]

22. Gunawardena, C.N.; Wilson, P.L.; Nolla, A.C. Culture and online education. In Handbook of Distance Education; Moore, M.G., Anderson, W.G., Eds.; Lawrence Erlbaum: Mahwah, NJ, USA, 2003.

23. Chan, B. A study of the relationship between tutor's personality and teaching effectiveness: Does culture make a difference? Int Rev. Res. Open Distrib. Learn. 2002, 3, 1-21. [CrossRef]

24. Gunawardena, C.; Nolla, A.C.; Wilson, P.L.; Lopez-Islas, J.R.; Ramirez-Angel, N.; Megchum-Alpizar, R.M. A cross-cultural study of group process and development in online conferences. Distance Educ. 2001, 22, 85-121. [CrossRef]

25. Wang, M. Designing online courses that effectively engage learners from diverse cultural backgrounds. Br. J. Educ. Technol. 2007, 38, 294-311. [CrossRef]

26. Strang, K.D. Multicultural e-Education: Student learning style, culture and performance. In Handbook of Research on Human Performance and Instructional Technology; Song, H., Kidd, T., Eds.; IGI Global: Hershey, PA, USA, 2010; pp. $392-412$.

27. Hall, E. Beyond Culture; Anchor Press: New York, NY, USA, 1976.

28. Bozkurt, A.; Akbulut, Y. Dropout patterns and cultural context in online networked learning spaces. Open Prax. 2019, 11, 41-54. [CrossRef]

29. Liu, Z.; Brown, R.; Lynch, C.F.; Barnes, T.; Baker, R.; Bergner, Y.; McNamara, D. MOOC learner behaviors by country and culture: An exploratory analysis. In Proceedings of the 9th International Conference on Educational Data Mining, Raleigh, NC, USA, 29 June 2016-2 July 2016.

30. Hofstede, G. National cultures in four dimensions: A Research-based theory of cultural differences among nations. Int. Stud. Manag. Organ. 1983, 13, 46-74. [CrossRef]

31. Triki, A.; Bay, D.; Cook, G.L.; Law, D. Hofstede's cultural dimensions and accountants: A Re-Analysis and some further evidence from Tunisia. In Proceedings of the CAAA Annual Conference, Charlottetown, PEI, Canada, 13 January 2012.

32. Tlili, A.; Wang, H.; Gao, B.; Shi, Y.; Zhiying, N.; Looi, C.K.; Huang, R. Impact of cultural diversity on students' learning behavioral patterns in open and online courses: A lag sequential analysis approach. Interact. Learn. Environ. 2021, 1-20. [CrossRef]

33. Marambe, K.N.; Vermunt, J.D.; Boshuizen, H.P. A Cross-cultural comparison of student learning patterns in higher education. High. Educ. 2012, 64, 299-316. [CrossRef]

34. Nistor, N.; Gögüş, A.; Lerche, T. Educational technology acceptance across national and professional cultures: A European study. Educ. Technol. Res. Dev. 2013, 61, 733-749. [CrossRef]

35. Viberg, O.; Grönlund, A. Cross-cultural analysis of users' attitudes toward the use of mobile devices in second and foreign language learning in higher education: A case from Sweden and China. Comput. Educ. 2013, 69, 169-180. [CrossRef]

36. Hofstede, G. Dimensionalizing cultures: The Hofstede model in context. Online Read. Psychol. Cult. 2011, 2, 2307-0919. [CrossRef]

37. Moss, G.; Kubacki, K.; Hersh, M.; Gunn, R.O.D. Knowledge management in higher education: A comparison of individualistic and collectivist cultures. Eur. J. Educ. 2007, 42, 377-394. [CrossRef]

38. Cambridge, J. Investigating national and organizational cultures in the context of the international school. In International Education: Principles and Practice; Hayden, M., Thompson, J., Eds.; Routledge: London, UK, 2012; pp. $197-211$.

39. Hofstede, G. Cultures and Organizations: Software of the Mind; McGraw-Hill: London, UK, 1991.

40. Al-Harthi, A.S. Distance higher education experiences of Arab Gulf students in the United States: A cultural perspective. Int. Rev. Res. Open Distrib. Learn. 2005, 6, 1-14. [CrossRef]

41. Wang, H.; Tlili, A.; Zhong, X.; Cai, Z.; Huang, R. The impact of gender on online learning behavioral patterns: A comparative study based on lag sequential analysis. In Proceedings of the 2021 International Conference on Advanced Learning Technologies (ICALT) IEEE, Online, 29 January 2021; pp. 190-194.

42. Yukselturk, E.; Bulut, S. Gender differences in self-regulated online learning environment. J. Educ. Technol. Soc. 2009, 12, 12-22.

43. Astleitner, H.; Steinberg, R. Are there gender differences in web-based learning? An integrated model and related effect sizes. AACE Rev. (Former. AACE J.) 2005, 13, 47-63.

44. Best, D.L.; Williams, J.E. A cross-cultural viewpoint. In Perspectives on the Psychology of Gender; Beall, A.E., Sternberg, R.J., Eds.; Guilford Press: New York, NY, USA, 1993; pp. 215-248.

45. Rogoff, B.; Gauvain, M.; Ellis, S. Development viewed in its cultural context. In Developmental Psychology: An Advanced Textbook; Bornstein, M.H., Lamb, M.E., Eds.; Erlbaum: Hillsdale, NJ, USA, 1984; pp. 533-571.

46. Lummis, M.; Stevenson, H.W. Gender differences in beliefs and achievement: A cross-cultural study. Dev. Psychol. 1990, 26, 254. [CrossRef]

47. Norris, P.; Inglehart, R. Islam \& the West: Testing the Clash of Civilizations Thesis; John, F., Ed.; Harvard University: Cambridge, UK, 2002.

48. EDUCAUSE. 2021 EDUCAUSE Horizon Report Teaching and Learning Edition. Available online: https://www.learntechlib.org/ p/219489/ (accessed on 1 August 2021). 
49. Hamdan, A.K. The reciprocal and correlative relationship between learning culture and online education: A case from Saudi Arabia. Int. Rev. Res. Open Distrib. Learn. 2014, 15, 309-336. [CrossRef]

50. Khayati, A.; Ariail, D.L. Business students' perceptions of faculty attributes: A two-country cross-cultural comparison. Account. Educ. 2020, 29, 153-176. [CrossRef]

51. Yang, X.; Wang, H.; Li, J. The application of lag sequential analysis method in analyzing learning behavior. China Educ. Technol. 2016, 2, 17-23.

52. Wagner, E.D. Becoming a Learning Designer. In Design for Learning: Principles, Processes, and Praxis; McDonald, J.K., West, R.E., Eds.; EdTech Books, Brigham Young University: Provo, UT, USA, 2021; Available online: https://edtechbooks.org/id (accessed on 4 November 2021).

53. Liu, S.; Liang, T.; Shao, S.; Kong, J. Evaluating localized MOOCs: The role of culture on interface design and user experience. IEEE Access 2020, 8, 107927-107940. [CrossRef]

54. Fisher, I.; Ziviani, J. Explanatory case studies: Implications and applications for clinical research. Aust. Occup. Ther. J. 2004, 51, 185-191. [CrossRef]

55. Hofstede Insights: Country Comparison. Available online: https://www.hofstede-insights.com/country-comparison/ (accessed on 27 August 2021).

56. Messner, W. The institutional and cultural context of cross-national variation in COVID-19 outbreaks. Medrxiv 2020. [CrossRef]

57. Lipsey, M.W.; Wilson, D.B. Practical Meta-Analysis; SAGE publications, Inc.: Thousand Oaks, CA, USA, 2001.

58. Sackett, G.P. The lag sequential analysis of contingency and cyclicity in behavioral interaction research. In Handbook of Infant Development, 1st ed.; Osofsky, J.D., Ed.; Wiley: New York, NY, USA, 1979; pp. 623-649.

59. Chen, B.; Resendes, M.; Chai, C.S.; Hong, H.Y. Two tales of time: Uncovering the significance of sequential patterns among contribution types in knowledge-building discourse. Interact. Learn. Environ. 2017, 25, 162-175. [CrossRef]

60. Bakeman, R.; Quera, V. Analyzing Interaction: Sequential Analysis with SDIS and GSEQ; Cambridge University Press: New York, NY, USA, 1995.

61. Noorani, K.H.; Zandi, B.; Sarmad, M.; Seraji, F. Cultural features of Iranian learners in the e-learning system. Q. J. Res. Sch. Virtual Learn. 2017, 5, 24-46.

62. Vermunt, J.D.; Vermetten, Y.J. Patterns in student learning: Relationships between learning strategies, conceptions of learning, and learning orientations. Educ. Psychol. Rev. 2004, 16, 359-384. [CrossRef]

63. Lewis, R.D. The Cultural Imperative: Global Trends in the 21st Century; Intercultural Press: Yarmouth, ME, USA, 2003.

64. Sun, N.; Rau, P.P.L.; Ma, L. Understanding lurkers in online communities: A literature review. Comput. Hum. Behav. 2014, 38, 110-117. [CrossRef]

65. Tu, C.H. How Chinese perceive Social Presence: An examination of interaction in online learning environment. Educ. Media Int. 2001, 38, 45-60. [CrossRef]

66. Ladson-Billings, G. Toward a theory of culturally relevant pedagogy. Am. Educ. Res. J. 1995, 32, 465-491. [CrossRef]

67. Marrone, M.; Mantai, L.; Luzia, K. MOOCs-what's cultural inclusion got to do with it? In Proceedings of the ASCILITE-Australian Society for Computers in Learning in Tertiary Education Annual Conference, Sydney, Australia, 1-4 December 2013.

68. Denden, M.; Tlili, A.; Essalmi, F.; Jemni, M.; Chen, N.S.; Burgos, D. Effects of gender and personality differences on students' perception of game design elements in educational gamification. Int. J. Hum.-Comput. Stud. 2021, 154, 102674. [CrossRef]

69. Jung, I. Cultural influences on online learning. In Culture and Online Learning: Global Perspectives and Research; Jung, I., Gunawardena, C.N., Eds.; Stylus Publication: Sterling, VA, USA, 2014; pp. 15-24.

70. Kang, H.; Chang, B. Examining Culture's Impact on the Learning Behaviors of International Students from Confucius Culture Studying in Western Online Learning Context. J. Int. Stud. 2016, 6, 779-797.

71. Altbach, P.G. MOOCs as Neocolonialism: Who Controls Knowledge? Int. High. Educ. 2014, 75, 5-7. [CrossRef]

72. Koseoglu, S.; Bozkurt, A. An examination of \#DigPed narratives through the Lens of the Capacities and Signals Framework. In Proceedings of the Ireland International Conference on Education (IICE-2018), Dublin, Ireland, 23-26 April 2018 ; pp. 124-125.

73. House, R.J.; Hanges, P.J.; Javidan, M.; Dorfman, P.W.; Gupta, V. Culture, Leadership and Organizations: The GLOBE Study of 62 Societies; SAGE Publications: Thousand Oaks, CA, USA, 2004.

74. Ess, C. When the solution becomes the problem: Cultures and individuals as obstacles to online learning. In Learning Cultures in Online Education; Goodfellow; Lamy, M.R., Ed.; Continuum: London, UK, 2009; pp. 15-29.

75. Chen, S.J.; Hsu, C.; Caropreso, E. Cross-cultural collaborative online learning: When the west meets the east. In Proceedings of the E-Learn 2005-World Conference on E-Learning in Corporate, Government, Healthcare, and Higher Education, Vancouver, BC, Canada, 24-28 October 2005; Association for the Advancement of Computing in Education (AACE): San Diego, CA, USA, 2005; pp. 1931-1941. Available online: https:/ /www.learntechlib.org/primary/p/21480/ (accessed on 1 August 2021).

76. Keller, J.M.; Ucar, H.; Kumtepe, A.T. Culture and motivation in globalized open and distance learning spaces. In Supporting Multiculturalism in Open and Distance Learning Spaces; Toprak, E., Kumtepe, E., Eds.; IGI Global: Hershey, PA, USA, 2018; pp. 146-165. [CrossRef] 